A. LÓPEZ-MAGANO, B. ORTÍN-RUBIO, I. IMAZ, D. MASPOCH, J. ALEMÁN*,

R. MAS-BALLESTÉ* (UNIVERSIDAD AUTÓNOMA DE MADRID, SPAIN)

Photoinduced Cross-Coupling with a Supported Iridium-Nickel Bimetallic Catalyst

ACS Catal. 2021, 11, 12344-12354, DOI: 10.1021/acscatal.1c03634.

\title{
Photoinduced Cross-Coupling with a Supported Iridium-Nickel Bimetallic Catalyst
}

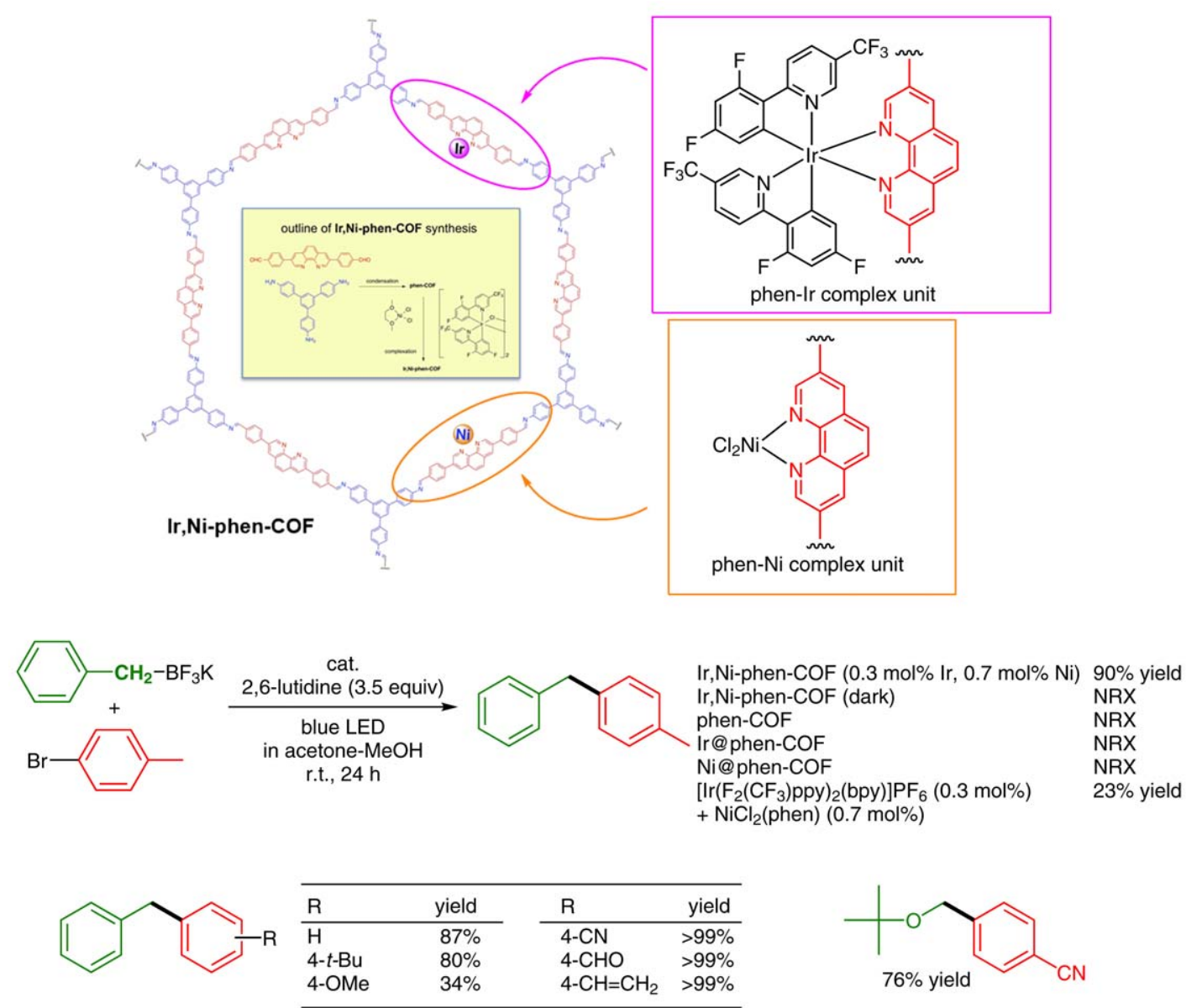

Significance: A covalent organic framework containing phenanthroline units (phen-COF) was prepared by condensation of 1,3,5-tris(4-aminophenyl)benzene with 3,8-bis(4-formylphenyl)-1,10phenanthroline. A heterobimetallic phen-COF composite, Ir,Ni-phen-COF, was obtained by complexation of phen-COF with $\left\{\left[\mathrm{F}_{2}\left(\mathrm{~F}_{3} \mathrm{C}\right) \mathrm{ppy}\right]_{2} \mathrm{Ir}-\mu\right.$ $\mathrm{Cl}_{2}\left[\mathrm{~F}_{2}\left(\mathrm{~F}_{3} \mathrm{C}\right)\right.$ ppy $]=$ 2-(2,4-difluorophenyl)-5-(trifluoromethyl)pyridine] and $\mathrm{NiCl}_{2}$-glyme. Ir,Ni-phen-COF catalyzed the $\mathrm{C}\left(\mathrm{sp}^{3}\right)-\mathrm{C}\left(\mathrm{sp}^{2}\right)$ bond-forming crosscoupling of alkylborates with aryl bromides under photoirradiation conditions.

\section{Category}

Polymer-Supported

Synthesis

Key words

covalent organic framework

iridium catalysis

nickel catalysis

photocatalysis

cross-coupling
Comment: The cross-coupling did not take place in darkness. Heterogeneous Ir,Ni-phen-COF exhibited a better catalytic performance than homogeneous bimetallic systems using ppy-Ir and phen-Ni complexes [e.g., 4- $\mathrm{MeC}_{6} \mathrm{H}_{4} \mathrm{Bn}$; yield: $90 \%$ (heterogeneous); $23 \%$ (homogeneous)]. Ir,Ni-phen-COF was recovered by centrifugation and reused seven times with a slight loss of its catalytic activity. 